\title{
The ecological crisis, the human condition, and community-based restoration as an instrument for its cure
}

\author{
Peter Leigh* \\ National Oceanic and Atmospheric Administration, Office of Habitat Conservation, 1315 East-West Hwy, Bldg 3, Rm 14729, \\ Silver Spring, Maryland 20910, USA
}

\begin{abstract}
We have entered an unprecedented period in human history. By the vigor of our consumption and procreation, the human species has modified our global environment at wide regional and global scales. At the close of the twentieth century, global warming, biodiversity losses, ozone and freshwater depletion, to name a few, are now recognized as human-induced wide-scale environmental transformations. In spite of admirable efforts to arrest some of these processes and restore environmental vitality, the pace at which humans modify their environment continues with considerable intensity. The future health of the biosphere for sustaining all life may be drifting close to the margins as environmental crises increase within a single generation. These destructive propensities have deep cultural and psychological roots that divide us from the rest of the environment. Significant social change is needed for improving our collective relationship with the earth. Humans, with our unique capacity for self-reflection, are beginning to understand that the underpinnings to our current ecological problems lie within our attitudes, values, ethics, perceptions, and behaviors. New ways to reconceptualize our unity with the biosphere, understand downstream impacts, and link social behavior with environmental transformations are increasing with corresponding intensity. Community-based restoration is a powerful means for facilitating this trend, by reconnecting communities with their landscape, empowering citizenry, and fostering an environmental ethos based on ecopsychological health.
\end{abstract}

KEY WORDS: Ecopathology $\cdot$ Environmental civics $\cdot$ Empowerment $\cdot$ Social change $\cdot$ Communitybased restoration $\cdot$ Ecopsychology $\cdot$ Biodiversity $\cdot$ Ecosystems

Resale or republication not permitted without written consent of the publisher

The next century will, I believe, be the era of restoration in ecology.

Edward O. Wilson, 1992

\section{THE ECOLOGICAL CHALLENGE}

There is a growing belief that the global ecological crisis which confronts humanity today is one of the most critical turning points that human civilization has ever faced. The causes of this trend are believed by some to lie in environmentally destructive propensities that create ecological imbalances. The basis for these imbalances can be ascribed to many forces, but can be largely reduced to a few central trends, the intensity of human consumption multiplied by sheer human numbers, combined by the lack of will to change, or worse, to fundamentally understand how our behaviors today are producing tomorrow's problems. None of these forces appear to be receding as global population and human consumption continue unabated with societies more inclined to watch, register, and witness these trends than to actively seek solutions. Global population is projected to continue to increase, but few demographers are certain if and when human popula- 
tion will stabilize and at what level; projections vary widely from 7 to 15 billion inhabitants by the end of this century.

War, disease, and technological constraints were once powerful controls to population growth. It is difficult to view these controls in a positive light and yet with advances in agriculture, the emergence of machinery, and medical innovation, global populations have risen with exponential swiftness. Influenza took three quarters of a million Americans in 1918, and possibly 30 to 50 million people world-wide. Tuberculosis, yellow fever, malaria, influenza, polio, pneumonia and numerous other diseases served as a natural force that constrained life expectancy. Europe during the Middle Ages lost $25 \%$ of its population to the bubonic plague. These diseases once served as a powerful natural control on population growth, since many of them particularly struck the young with a vengeance, cutting short the opportunity to procreate. With the advance of sanitation, vaccines, antibiotics, and surgery, most of these problems were resolved with remarkable success.

Advances in medicine are expected to continue into this century with innovations that were once relegated to science fiction, including cloned and artificial organ replacements, genomic medicine, and even the possibility to control the rate of aging itself. To quote two leading world demographers, 'mortality research has exposed the empirical misconceptions and specious theories that underlie the pernicious belief that the expectation of life cannot rise much further' (Oeppen \& Vaupel 2002, p. 1031). Even divorced of the kind of biological revolutions that are being touted by molecular biologists to extend life beyond our wildest dreams, the US population alone is expected to exceed 400 million by the middle of the next century, adding the equivalent of Connecticut's population every year and California's every decade (President's Council 1996).

As technological innovation conspires to sustain life, each person continues to consume larger quantities of resources. In a society whose tenet rests with 'more is better' one could assume that the collection of more and more stuff is limitless. The very familiar cliche 'shop until you drop,' may soon take on global significance when applied to the biosphere, particularly if the projected world populations of 7 to 15 billion inhabitants becomes economically empowered in this century. However, with the more is better principle one may ask, when is enough? Is there a point of material satiation? A growing number of mid-developed countries in the world are poised to emulate US consumption patterns. In China bicycles are being replaced by cars. India has over 100 million middle-class citizens with looming buying power. E. O. Wilson, a leading authority on biodiversity, recently stated, 'For every person in the world to reach present U.S. levels of consumption with existing technology would require four more planet earths (Wilson 2002, p. 23). The ecological footprint from each planetary resident expands as our limited land mass struggles to accommodate these growing demands, leaving behind the bucolic settings that once dotted our landscape (Fig. 1). Early pioneers of the New World arrived to the Americas thinking the land was an Eden of limitless bounty, and at that time, in relation to human populations, it was.

By the close of the twentieth century nowhere on earth held claim of not being influenced by human activity. Pollution has extended its reach into remote regions of the world. Pesticides and other toxic materials used in agriculture and industry are transporting chemicals, known as organochlorine compounds, to the most frigid uninhabitable polar regions on earth. This is done by a process of atmospheric uptake that can carry these chemicals over great distances. Once vaporized these compounds can travel intercontinentally to be later deposited by means of rain and snow (Blais et al. 1998). Even where the most laudable efforts are now underfoot to create or expand marine and terrestrial sanctuaries, human influences cast their signal from a distance (Grossman 2004). A coherent fingerprint of climate change impacts across natural

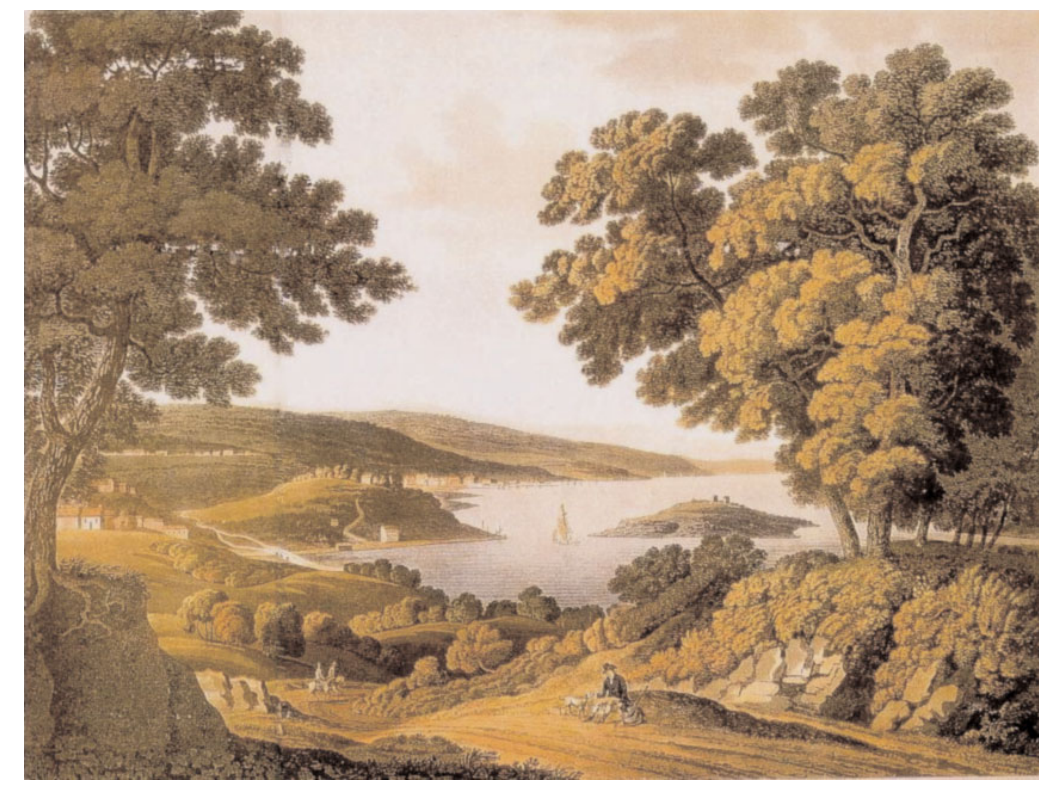

Fig. 1. The forest and farms marked the scene of Washington, DC, encountered when landscape painter George Beck arrived in America in 1795 (Miller 2002) (Public domain) 
systems was recently established by Parmesan and Yohe. Their finding has documented a significant northward species range shift averaging $6.1 \mathrm{~km}$ for 279 species with a mean advancement in spring events by 2.3 days per decade (Parmesan \& Yohe 2003). This finding confers increased confidence in the International Panel for Climate Change assessment that climate will affect living systems.

Similarly, efforts to identify biodiversity hot spots throughout the world in order to define conservation priorities for sustaining the most species at the least cost (Myers et al. 2000), an otherwise logical approach for preservation, hinges on the assumption that biological communities are reasonably area bound, stable, and cohesive. However, according to current thinking on global warming theory, increased global temperatures will likely act on the two master variables of life on earth, temperature and precipitation, with the potential likelihood of radically reconfiguring species' distributions. Adding to this reconfiguration, at least within the marine environment, is evidence that the oceans are warming. To quote a leading oceanographer with the National Oceanic and Atmospheric Administration, S Levitus, 'Our results demonstrate that a large part of the world ocean has exhibited coherent changes of the ocean heat content during the past 50 years... the whole-Earth system has gone into a relatively warm state' (Levitus et al. 2000, p. 2226).

Greenhouse skeptics always pointed to the modest increase in atmospheric warming, given the levels of greenhouse gases, in that warming should be twice the current level, and climate modelers always countered that the ocean must be soaking up the heat, but no-one really knew. Now their claim appears to be fortified, but one lingering question remains: How long can the ocean serve as a heat sink for the atmosphere? As recently as $11650 \mathrm{yr}$ ago, a change in average temperature as great as $10^{\circ} \mathrm{C}$ may have occurred within a narrow window of 20 yr (Taylor 1999). Natural system transformations, even without anthropogenic forcing, are notoriously non-linear. One of the most towering conundrums in global environmental assessments is that one knows one has a sustainable system only after the fact (Costanza 1996). In other words, optimum levels of environmental exploitation are often a function of trial and error as sustainability often defies prediction. The predicament is exacerbated when gyrations in natural variability mask the effects of overexploitation. Fisheries ecologist J. Magnuson refers to this as the invisible present, where ecosystem changes are initially slow and imperceptible and occur over time scales that exceed most research windows; a situation that preconditions us toward a greater probability for serious environmental misjudgements and surprises (Magnuson 1990).
For global warming such masking looms large, particularly when faced with likely irreversibilities and potentially sizable consequences. You do not need a depth of knowledge in ecology to know that major shifts in temperature, salinity, precipitation, ocean circulation, etc., can swiftly and radically alter biotic zones, and reconfigure the food source for all species on Earth. There is, one presumes, a critical mass of biota needed for sustaining planetary geophysiology. The average adult lungs harbor about 600 million alveoli. From a microcosmic view, it may seem like an infinite resource, but remove large masses of lung tissue and degeneration will follow, often abruptly. As one of the world's leading ecotoxicologists once conveyed, 'there is little doubt that practices tolerated on earth, such as population growth, overexploitation of ecological capital, and massive destruction of habitats and species, could not be tolerated in Biosphere 2 (human constructed terrarium) even for a short time' (Cairns 1996, p. 15). The stability of the biosphere is illusionary as its equilibrium is periodically interrupted with punctuated events that we are beginning only now to discern (Sagan \& Margulis 1989). As one of the world's prominent climate scientists recently stated about abrupt climate change, '....it is clear that Earth's climate system has proven itself to be an angry beast. When nudged, it is capable of a violent response' (Broecker 2003, p. 1522). Natural climate transition is generally episodic and denoted by rapid phase transformation (Sirocko 2003). From chaos and control theory, and from physiology, perturbations of a system that is close to instability can lead to oscillations, chaotic change, or failure (Bak \& Chen 1991, Hansen 2005).

The ability of our species to transform the biosphere has reached unprecedented heights as the probability of reaching a critical mass approaches a statistical certainty. Humanity faces fundamental questions about the sustenance of nature and society as it approaches critical crossroads in this century. As one authority on sociobiology stated, 'The human species is, in a word, an environmental abnormality. It is possible that intelligence in the wrong kind of species was foreordained to be a fatal combination for the biosphere' (Wilson 1993, p. 25). Therefore, a reassessment of some of the pathways that connect social behavior with environmental transformations is needed. To a neutral observer one may ask, how did we, as a species with crowning intelligence, come to this precipice? Why, as a species with a unique capacity for foresight, creativity, and inventiveness, are we drifting dangerously close to destabilizing our planet and what remedies are available to counter these seemingly irrevocable trends? We appear to be on an relentless path of environmental degeneration without a sense of consequence for planetary survival. 
As the editors of Scientific American recently stated about events leading to the Columbia space shuttle disaster that has analogous connections to our plight, 'Events... showed that the space agency still had not learned how to listen to the cautions of its own personnel' (Rennie et al. 2003, p. 10). 'Ruin is the destination toward which all men rush...' commented G Hardin in one of his landmark papers (Hardin 1968, p. 1244) or as Harvard's authority on biodiversity asked, 'is humanity suicidal?' (Wilson 1993, p. 24)

\section{ECOPSYCHOLOGY AND THE HUMAN CONDITION}

Ecopsychology is a new discipline that integrates the science of psychology with ecology, in that it brings mainstream psychological theory into the foreground for better understanding our relation with the environment. Its central tenet is the recognition that human health is intrinsically connected to the health of the planet and that both are mutually inclusive of the other. Ecopsychology draws upon the ecological sciences to reexamine the human psyche as an integral part of the web of nature. This new science adds depth to our analysis for better understanding our destructive propensities and for recognizing that constraining the scramble for profits or enacting more laws and regulations are not the only tools for promoting environmental conservation. Rather, a deeper probing into our destructive environmental attitudes toward nature is also a critical consideration for fostering a healthier and more sustainable relationship with our landscape, for, as one scientist stated, '...sustainability is a particular relationship of the human species with the entire biosphere' (Cairns 2000, p. 1).

A central starting point for understanding our destructive environmental behavior is to first understand our social psychology. Freud once addressed the issue of communal pathology by stating, 'If the development of civilization has such a far-reaching similarity to the development of the individual... may we not be justified in reaching the diagnosis that some civilizations, or some epochs of civilization, possibly the whole of mankind, have become neurotic' (Freud 1961, p. 91). K Lorenz, ethnologist and authority on aggression, complemented these views by conveying that intra-specific selection bred into man a measure of aggression for which in the social order of today he finds no adequate outlet (Lorenz 1963). One of the central observations of human history is that of aggression and murder, directed toward other races, nations, religions, social groups, clans. Psychiatrist RD Laing reinforces such claims by stating, 'In the last fifty years, we human beings have slaughtered, by our own hands, one hundred million of our species' (Laing 1967, p. 76). Therefore, our environmental maleficence may be but a logical extension from this historical record of violent social pathology.

Such dour assessments of the human condition cross many fields and time periods but cluster around a central archetypical theme, that something is not quite right with the human species. The centerpiece for most romantic themes is marked by humanity's alienation, division, and duality from God, his fellow man, and him/herself. Milton's Paradise Lost, Blake's Book of Urizen, or Godwin's Caleb Williams represent the Promethean imperfections of a species gone awry. Even Shelley's familiar Gothic story of Frankenstein metaphorically captures the central duality of our antithetical halves of a single being, wherein the monster and creator are one. Although religious, mythological, and romantic literature is littered with stories of humanity's fall from grace, an early passage from Plato's cosmology eloquently captures this repeating motif, "The motions akin to the divine part in us are the thoughts and revolutions of the universe; these, therefore, every man should follow, and correcting those circuits in the head that were deranged at birth, by learning to know the harmonies and revolutions of the world...' (MacDonald 1952, p. 354).

This claim is strikingly complementary to more modern scientific insights where neurologist P Maclean, foremost expert on limbic brain physiology, advanced the idea that our nervous system has evolved three superimposed brain structures characterized by reptilian, paleomammalian, and neomammalian lines of development (MacLean 1973). Each brain having its own chemistry and distinct function; each desynchronized with the other to produce a condition of schizophysiology, his coined term (MacLean 1958). In a sense, we have three conjoined brains in psychophysiological dissonance where anatomy outpaced function. It suggests that the transduction of consciousness is fractured through the prism of a divided physiology. D Morris and $\mathrm{K}$ Lorenz reinforced this dichotomy by asserting that our pathological condition has a phylogenetic basis pre-wired and programmed into our central nervous system (Lorenz 1963, Morris 1967). As MacLean states, the lower reptilian brain lacks the neural machinery for learning to cope with new situations with a distinct propensity toward repeating patterns of behaviors (MacLean 1964). Such insights give Freud's view of man's seemingly inescapable compulsion to repetition special meaning (Freud 1959), an observation vigorously reinforced by Hegel's maxim, 'What experience and history teach us is this... that people and governments have never learned anything from history, or acted on principles deduced from it' (Hegel 1956, p. 6). 
However, if humans are under the tight control of a neural program that prevents them from extricating themselves from fixed patterns of behavior, with a prewired tendency to clan with only family or tribe, then how can a global environmental commitment ever be realized? Or as one biologist recently stated, 'Compelling evidence shows that all culture is learned. But its invention and transmission are biased by innate properties of the sensory system and brain' (Cairns 1998, p. 7). Does the neural software operating in humankind in the past 200,000 years preclude 'hive' first efforts to commit to the commons, particularly when environmental impacts may be decades into the future (e.g. global warming)? As one of the leading authorities of modern behaviorism, BF Skinner, once stated related to voluntary behavior, '...it is never a future consequence which is effective. A change in practice is made because similar changes have had certain consequences in the past' (Skinner 1956, p. 428). 'Operant learning is difficult when reinforcement lies far into the future or punishing consequences are unclear, uncertain, or remote'. Clearly, the context for defining sanity in our time has reached planetary dimensions. The question for the human species is whether humanity will master and overcome this instinctual propensity toward aggression and repeating self-destruction as so well documented by Freud, Laing, and Lorenz.

However, our species may yet be redeemed from this Promethean fire. We may have the capacity to transcend our destructive propensities. As the fledgling science of psychobiology advances, prospects for mapping the very origin and meaning of human values, from which all ethical pronouncements and principles are derived, may one day be realized. The interior psyche of humankind might soon be investigated and neurophysiologically mapped for realizing Freud's dream for grounding psychology to physiology (Restak 1991). Contrary to long-held beliefs, the structure of the human brain is not fixed, but plastic. The extent of our neuroplasticity is a focal point of intense research; nevertheless, evidence over the past two decades reveal reasons for optimism (Holloway 2003). Psychobiology is in the earliest phase of deducing the mechanisms that guide and explain human behavior. In this dawn are intimations science may be poised to help us actualize the brain's potential for bridging the phylogenetic rift between old and new brain, emotion and reason, instinct and intellect, for addressing our social and environmental ills.

Prominent social theorists such as Spengler, Vico, Marx, Teggart, and Spencer have exalted impressive social theorems, but they were divorced of psychobiological principles that are only now coming to light. To what extent does brain circuitry, encoded by the genes, preordain the direction of social development and environmental values? How can we alter human behavior to promote a more constructive and enlightened relationship with ourselves and our environment? In other words, the underpinnings of improved ethics in environmental politics may rest on the psychic life of the planet's inhabitants who have nurtured a broader view of self. A leading physicist of the last century summarizes this theme best:

\begin{abstract}
A human being is part of a whole, called by us the universe, a part limited in time and space. He experiences himself, his thoughts, and feelings, as something separate from the rest, a kind of al delusion of his consciousness. This delusion is a kind of prison for us. Restricting us to our personal desires and to affection for a few persons nearest us. Our task must be to embrace all living creatures and the whole of nature in its beauty. 'Albert Einstein (Calaprice 2000, p. 316)'
\end{abstract}

The transition of consciousness toward a more comprehensive identification of self with the environment may be the bedrock of a needed social transformation as we enter, to quote A Koestler, 'the age of climax' (Koestler 1967, p. 313).

\section{ECOPSYCHOLOGY PRINCIPLES}

Although ecopsychology is an emerging science, attempts to systematically identify psychological principles to explain our relationship with the natural world are being explored along several central themes: environmental autism, denial, consumer addiction, narcissism, amnesia and dissociation, to name a few. Ecoautism represents a psychopathological metaphor where the human species has become autistic in relation to the natural world (Berry 1988, Roszak 1992, Metzner 1999). We have the knowledge of our impact on the environment but choose to ignore it, a species in denial. Autism, a form of child psychosis, is characterized by a sensory shut down in which a child fails to respond emotionally to the presence of his/her mother and does not appropriately respond to gesture, voice, or touch, often lacking empathy for others. These characteristics are being paralleled to our industrial culture that reflects a form of autism to our natural surroundings in that humanity appears to be detached from the scale at which we are modifying our global environment (Turner et al. 1990).

A second theme is our technological addiction and dependencies across the entire range of consumer products. Our addiction, marked by psychological dependencies, like all addictions, is slow and imperceptible. It proceeds like a progressive disease that begins to alter our psychological processes along a 
path of aimless compulsions marked by, not unlike alcoholism, early denial. Eventually, the addiction leads to depraved changes in attitude, behavior, and life-style, culminating in a breakdown. We perceive the pollution and degradation of the land, water, air, and ocean, but are powerless to stop it. A third psychological model is narcissism, a personality disorder characterized by a severe inflation of the self. Extended to ecopsychology, this characteristic corresponds to environmental chauvanism, the crown of creation complex, marked by a sense of biological supremacy and dominance over all forms of life. On a collective scale, such lack of personal fulfillment leads to an alienation from nature and anthropocentric arrogance that is ultimately destructive to both the individual, society, and the environment. The final diagnostic analogy is that humanity is suffering from a collective amnesia, in that we have forgotten our former closeness with the Earth. Plato's insights on the origin of knowledge conveyed the concept of universal ideas and truths lost at birth, but which through philosophy can be recalled (Jowett 1937). If this is extended to humanity's interdependent relationship with the environment, it seems we have forgotten what was once natural for indigenous cultures as their constant dependancy on nature was an ineluctable truth, daily reinforced.

Changes in technology and modes of production have fundamentally altered the relationship between people and natural ecosystems. When people were sustained by hunting and gathering the availability and distribution of plant and animal foods limited human population abundance and distribution; hunter-gatherer culture was tightly integrated into food webs. The dependence of humans on natural stocks of plants and animals declined with the advent of agriculture, which allowed people to concentrate in areas with high agricultural productivity, areas where soils were fertile and rainfall abundant. No longer was the spatial distribution of people limited by the availability of prey. Augmentation of rainfall with irrigation and the addition of fertilizers to natural stocks of nutrients further reduced the spatial dependence of human population centers on the biotic and abiotic properties of ecosystems. Furthermore, the advent of extensive transportation networks and the development of food-preservation technologies during the industrial revolution extended the habitable area for humans by allowing population of areas remote from agriculture. As a result, human constraints on food sources were liberated and human migration occurred swiftly across all continents. All these trends progressively decoupled the closeness humans had to their environment for sustenance.

\section{COMMUNITY-BASED RESTORATION AS AN INSTRUMENT FOR SOCIAL CHANGE}

Community-based restoration is a novel, grassroots approach that actively engages local communities in ecological restoration of habitats. The practice brings communities together, promotes a conservation ethic, and develops a sense of place. By this action, humanity reconnects with the environment, often in meaningful ways, to heal a segment of an impaired earth. The exercise fosters an emotional commitment to a particular part of a landscape or seascape, that often, inadvertently, fosters a sense of ownership of the commons. It does something more than 'passive' environmental activities such as hiking, wildlife viewing, or environmental preservation, as it presents each participant with an environmental problem along with an active on-theground restoration solution, a solution for which each volunteer is a part, often with tangible results.

In a time of increasing despair over the scope and scale of human impacts on the environment and as habitats are degraded or contract by the minute, restoration offers a means to positively shift the environmental ledger back in favor of natural systems. It provides local empowerment through which people from diverse backgrounds can come together and channel their environmental commitments to positively influence a part, however small, of an ecosystem. These acts serve as a powerful social statement to the rest of the community, if not the world, that a portion of its citizenry can make a difference, even if it is the last remnants of nature that is being restored; that they can, by their efforts, hard work, and sacrifice, demonstrate to others that a small group of dedicated people are meeting their obligations to future generations, other species, and entire ecosystems by redeeming both nature and humanity by restoring places of beauty and ecological importance.

Restoration, community-inspired, offers reciprocity and redemption to give back to nature for what nature has given to us and for what we have taken from it. It offers the average citizen not only insight on how humans impact their immediate landscape, but the larger biotic community as a whole, an insight that perhaps can be viewed as more valuable than the ecological restoration itself. The environmental crisis and its connections to pollution, overdevelopment, population, consumption, and scarcity are strikingly realized by community volunteers when the parcel of their restored landscape is shown to be affected by these forces. Global environmental change is often too elusive to grasp, yet, like an odorless poison, too profound to ignore. Those that gently tend to a portion of a renewed Earth are given, often unknowingly, a gratuitous grace. Nature, under this healing paradigm, is no 
longer possessed but nurtured, no longer rendered dysfunctional, but reborn.

Community-based restoration serves as an instrument for social change by promoting a deeply committed constituency, a constituency which is critical for addressing environmental problems at all geographical scales. A sense of kinship often permeates the kind of bonding commonly observed by community-based participants. An intuitive kindred, an extended family mind-set, emerges among restoration participants marked by a special psychological dimension, an emotional dimension, that these shared acts to improve the environment engenders. Environmental stewardship comes by igniting the passion of those that live in the community to choose environmental sustainability. Community-based restoration is a powerful modality for sparking and sustaining this passion because as it mediates a new relationship with the natural world and transforms individual values into social values it helps forge collective purposes, and, even more importantly, helps define, direct, and shape public morality.

At the moment, this inspirational, even spiritual, restoration generally entails small-scale projects and therefore to an outside observer may represent only symbolic or ceremonial acts to improve natural systems. Also, because restoration is a new science, it is still challenging to achieve full functional returns to natural systems, but this deficit is a benefit that further reinforces the need for humanity to tread lightly on a fallen Earth. For these, and many other factors, help expand a constituency for valuing intact natural systems even more and serve as a foundation for fundamental changes in behavior necessary if we ever hope to achieve environmental sustainability. For the act of restoration beckons us, by the act to change a system back to a more self-sustaining ecology, to insightfully grasp the complexities of these hierarchical and heterarchical systems. It allows average citizens to fully grasp the challenges entailed to heroically resurrect a fallen system. More so, restoration not only attempts to reverse history, it allows us to time travel back to a previous period in our ecological past in a fierce effort to recapture a part of our lost Eden.

Currently, there are thousands of community-based restoration projects occurring in North America every year. The National Oceanic and Atmospheric Administration facilitates several hundred projects annually. ${ }^{1}$ For coastal and marine habitats, the ones my agency undertakes, restoration actions may include tidal marshes, wetlands, coral reefs, mangroves, seagrass beds, or kelp forests, to name a few. These habitats provide homes for marine mammals, foraging and nursery grounds for fish and shellfish, and nesting and

\footnotetext{
${ }^{1}$ See www.nmfs.noaa.gov/habitat/restoration
}

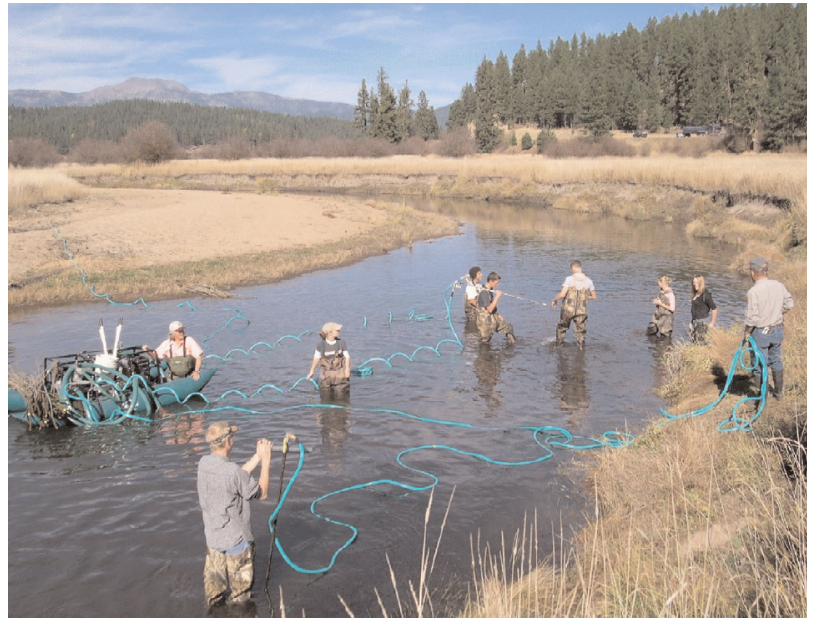

Fig. 2. Volunteers are sometimes enlisted to use equipment for facilitating planting along riverbanks. In this initiative a waterjet stinger is being employed (Kent Werlin) (By permission of photographer Kent Werlin)

migration corridors for birds. They also provide other services such as protection from wind, waves, and flooding, as well as benefits from tourism, commercial, and recreational industries. For example, the upper Little Salmon River in New Meadows, Idaho, flows through privately owned land for about 10 miles. Removal of streamside vegetation, channelization, and the increased presence of livestock during the past century have drastically altered natural processes. Where trees and shrubs once lined the river now crumbling cuts in the riverbanks commonly dot the landscape from changes in water flow patterns caused by human alterations of the landscape. Natural gravels that once served the riverbeds as spawning grounds for salmon are generally covered over from excessive sedimentation. Without riverside vegetation water temperatures soar during intense summer days, placing severe stresses on native species.

In the spring of 2004, a community-based restoration initiative mobilized numerous citizens to revegetate a riverbank along the Little Salmon River. Thousands of shrubs and trees were planted by committed volunteers, sometimes planting over 1000 units in a day. Over the past five years in the southwest region of the state over 1000 volunteers planted 258100 plants. $^{2}$ Sometimes volunteers are used for the simple planting of trees and vegetation, other times they may be enlisted to use a variety of equipment to expedite planting. For example, opportunities to employ volunteers for riparian revegetation using a waterjet stinger that uses a high pressure water forced technique with specially designed nozzles to efficiently bore holes for

\footnotetext{
${ }^{2}$ See http://www.mountainvisions.com
} 
planting dormant, non-rooted cuttings, is now a standard practice (Fig. 2). This method is limited to species that easily sprout from hardwood cuttings, such as willows, but this variety of species are very effective for achieving streambank stabilization and buffering riverbanks that in turn produce a more natural setting.

Through the work of Mary Dudley, volunteer coordinator for the Idaho Department of Fish and Game, along with Federal sponsorship from the National Oceanic and Atmospheric Administration, we are seeing the profound impact of meaningful volunteer restoration opportunities on the citizens of Idaho. Since 1990, Mary has provided a link between conservationminded Idaho citizens of all ages and backgrounds, resulting in ecologically functional wetland and riparian restoration. Each volunteer who works with Mary goes home with a deeper understanding of the importance of wetlands and riparian areas as fish and wildlife habitat. All participants benefit from the opportunity to return to a site to witness ecological recovery. Each volunteer gains a sense of empowerment related to his or her own impact on problems and landscapes that seem initially overwhelming. Mary and her program are contributing to the formation of lifelong watershed stewards who believe they can make a difference. A landowner who participated in one of Mary's restoration projects wrote, 'By educating the public about these environmental issues, and with the hands-on approach to activate that knowledge, an individual becomes better equipped and informed to make decisions as he/she develops a personal stake in affecting the environment. My husband and I believe that continued support for these areas of riparian restoration not only enhances the environment, but also plays an important role in educating the community' (pers. comm. from a landowner contained in a submitted community-based project application).

In tandem with community engagement as a social transforming agent is J Goodall's global initiate titled 'roots and shoots.' This is an international network for young people and their mentors committed to making a positive impact on communities and their environment by identifying problems and initiating actions. Currently there are over 3000 roots and shoots groups across 68 countries. Each group selects hands-on projects for improving the environment, the well-being of animals, and the human community. The core message is that every individual matters and can make a difference. Metaphorically, roots spread underground and make a firm foundation. Shoots seem small and weak, but to reach the light they can break through brick walls. The 'roots' are the people engaged in specific actions for attempting, often with young volunteers ('shoots'), to penetrate the walls (problems that humanity has inflicted on the planet). One example, on
Saturday, April 8, 2000, Salisbury State University Roots and Shoots initiated an effort to clean up the Nanticoke River, which empties into the Chesapeake Bay, by removing waste that once dotted this river. ${ }^{3}$

Another entry on the roster for community empowerment as a method for social transformation is Dr. Wangari Maathai, an African woman from Kenya. The Norwegian Nobel Committee recently awarded her the 2004 Nobel Peace Prize for her contribution to sustainable development, democracy, and peace. She pioneered the Green Belt Movement, which has championed environmental sustainability for her country through the simple act of planting trees. Its vision has been to create a society principled on self-determination, justice, equity, poverty reduction, environmental conservation, and restoration. Tree-planting, a form of restoration, serves as the instrument for not only ecological enhancements, but also political and social transformations. Today, the Green Belt Movement has over 600 community networks across Kenya that care for 6000 tree nurseries. This has resulted in the transformation of many landscapes by fortifying biodiversity through the protection and restoration of habitats, as well as the coalescence of a powerful political constituency. ${ }^{4}$

Perhaps what constitutes the real story is the transformation of Kenyans' attitudes toward the environment as a result of this movement. Increased awareness of the impacts of ecological decline has increased along with public interest in defending the environment, including the protection of forests, public parks, and open space. The simple act of tree-planting provided a starting point for other initiatives, including civic and environmental education, capacity building and advocacy. Through this exercise the public's understanding and insight that the environment is not a luxury, but rather intrinsic to the foundation of all economic development and prosperity, has emerged as a reinforcing theme, a theme that is starting to spread to neighboring nations. A Pan-African Green Belt Network was recently formed involving trained representatives from 15 African countries. As a result, several tree-planting initiatives have been established in East and Central Africa. ${ }^{5}$

As far back as 1982, biologist W Odum skillfully applied principles outlined by economist A Kahn (Kahn 1966) by transferring his premise of the 'tyranny of small decisions' as it related to market economics to environmental science. Odum postulated that many important impacts on the environment occurred from a series of small decisions that were made by small

\footnotetext{
${ }^{3}$ See http://www.janegoodall.org

${ }^{4}$ See http://www.wangarimaathai.com

${ }^{5}$ See Footnote 4
} 
groups of individuals resulting in big effects. These large effects were not a forethought, as decisions were never consciously made with cumulative impacts in mind. As a result, large environmental problems were often foisted upon us unwittingly (Odum 1982). For example, over half the coastal wetlands of the northeastern US were destroyed not by any explicit decree, but by the lack of attention to small unit changes in extensive wetland conversions that occurred within a narrow window of twenty years, 1950 to 1970 (Odum 1982).

There are many other examples in the history of environmental science of how we similarly stumbled into large-scale problems (e.g. stratosphere ozone depletion, amphibian declines, global warming, etc.). Just as regional, national, and global environmental problems are highly vulnerable to the tyranny of small decisions, the reassembly and protection of small ecological units can potentiate the reverse effect. The cumulative benefits of small decisions and activities can progressively add to the environmental ledger for countering the degeneration of an ecosystem. In a sense, community-based restoration works like the concept of reversed engineering, as small ecological units dotted throughout the environmental landscape are additively nourishing more and more components of the ecosystem toward broad-scale functionality and health.

Community-based restoration has become a therapeutic catalyst of exceptional power for allowing us to participate, once more, with the rest of the living kingdom in our effort to recapture the 'garden.' It helps us see the world in organismic terms rather than mechanistic ones, interacting fields rather than isolated parts, an extended ecological community in which we are a part, rather than isolated, competing, separate entities unrelated to the whole. It attempts, often unknowingly, to address the split in society and nature by grounding our relation with nature with the corresponding depths of our human psyche. It elicits what $M$ Thomashow defined as, 'bringing the biosphere home', by inserting the perceptual connections between our local and global environment (Thomashow 2002, p. 16). Community-based restoration is a powerful instrument to systematically address many of our destructive tendencies, and, in this exercise, to culturally transform society toward a saner, healthier relationship with the environment. It is both a treatment for our ecopathological condition as well as an indicator of our ecopsychological health. Based on the scale and scope of current human forces acting on the environment, a drastic and immediate revision of our behavior is needed to constrain human impacts. Given the rate of environmental degradation, we need a sea change in our thinking.
In preindustrial society, comprising hunters and gatherers, we were left with few alternatives but to directly interact with the environment for daily sustenance. Through that daily interaction co-dependency was an ineluctable truth, repeatedly reinforced by humanity's vulnerabilities to natural systems (e.g. floods, droughts, crop failures). Such a dependency often translated emotional feelings into dreams and mythological narratives, a necessary precondition for art and religious belief. The late scholar of mythology, $\mathrm{J}$ Campbell, once stated about the first evidence of art found in North American, French, and Spanish caves dating back to 40,000 years BC, 'One finds the mystery dimension of man's residence in the universe opens through the iconography of animal messengers' (Campbell 1951, p. 99). This was a time when predator and prey were integrated into a single shamic dance of hunt and hunted, the local landscape the theater, plants and animals the actors, as so well portrayed in these moving silhouettes. It was a time when our species reinforced daily our dependence on nature by enlivening myths through ritualistic dance.

At the center stage of the emergence of our environmental movement is a change in values, one that derives from a growing appreciation of our dependence on nature (Taylor 1986). By the process of physically modifying the environment, community-based restoration allows us to regain our relationship with the Earth (Schroeder 2000). It addresses the alienation between us and the natural world by inviting its citizenry back into the forest to heal the landscape, to commune with nature, and awaken our senses to the wilderness from which our ancestors emerged as the most dominant environmental force. It activates our primal intelligence in which our instinctive wisdom resides and which our industrial world represses. Like an alchemist of old who struggles to transmute lead into gold, the restorationists are themselves transmuted.

We read, with considerable detachment, about environmental impacts from a wide range of human activities, but often fail to directly experience these effects. Ecologists, since E Odum laid down the foundation of ecological principles forty years ago, have always emphasized the complexity of ecosystems by informing us about the labyrinth of interacting parts (Odum 1971). However, reading about these complex interactions has limited value. Community-based restoration allows the average citizen, by the immersion of all five senses, to experience this complexity first hand. Nature's voice is heard when every sensory modality is activated. A growing view among social scientists is that we can best understand, value, and respect nature by having a direct relationship with these systems (Sheldrake 1991, Roszak 1992, Metzner 1999), for how can a marriage be successful if we rarely see our partner? 
Somehow the hunt for groceries at our local convenience store shelters us, like the Elois in Wells' time machine, from experiencing where the food, fresh air, and water is coming from. As F Turner conveyed that, even when inside a forest, if asked, 'where is nature,' most answer 'out there,' nature is still perceived as 'out there,' rather than 'here' (Turner 1985, p. 46). We have an inherent sense of separation from our environment with few windows to the natural world but for, say, gardening. For many of us, as Turner points out, gardening is the last remnant of interaction with nature as we putter about in our flower beds and shift a plant here to there and observe the results (Turner 1985). Otherwise we are, to quote biologist $\mathrm{R}$ Sheldrake, '...essentially alien to the larger living community; we need to subject it to ourselves lest we are subjected to it' (Sheldrake 1991, p. 205). Or as one modern philosopher conveyed, 'You didn't come into this world. You came out of it, like a wave from the ocean. You are not a stranger here' (Watts 1966, p. 8). The environment is not an externality as claimed by economists, it is the system in which we are an intrinsic part; like a cell in a body, we are inseparably connected across a chain of 3.2 billion years in co-evolutionary time. If, as ecopsychologist T Roszak suggests, the '...repression of the ecological unconscious is the deepest root of the collusive madness in industrial society' (Roszak 1992, p. 320), then community-based restoration is our mandala toward our reunification. Gaia gains access to us through the door of active restoration.

There has been a conspicuous oversight by environmentalists to fully appreciate the ecological, political, social, and psychological value of restoration. To quote W Jordan, 'One after the other, for better part of a century, environmentalists of various persuasions have walked past this (ecological restoration) work, failing to recognize its value either as a conservation strategy or as a context for negotiating the relationship between our own species and the rest of nature' (Jordon 2000, p. 24). Environmentalists have tended to fail to fully recognize the efficacy of restoration as a legitimate tool for adding to the environmental balance sheet. This is partly understandable as restoration ecology is an emerging science and, not unlike any new science, has had many early challenges. Space exploration, computer, and medical technology are only a few examples of how basic science and engineering start out in the initial experimental stage often marked by high costs and failure rates.

Regulation is and will continue to be an essential force in environmental policy, but non-regulatory tools that rely on positive reinforcement are a fresh force for promoting the new paradigm that use incentives rather than sanctions to reverse course. Community-based restoration is an emerging model for addressing the unfinished business of environmental protection by going beyond statutory authorities. It also addresses the need to move to an innovative approach of environmental governance called for by national commissions as far back as 1971 that suggested, 'the U.S. statutory and regulatory regime is woefully inadequate, cumbersome, and sometimes even contradictory with respect to environmental policy.' For example the World Resource Institute stated that we need to move to a new paradigm for environmental action so that sustainable development can become a cultural norm (Underwood 1992). The foundation of such a norm was suggested over 25 yeaars ago by K Boulding when he stated, "A very important dynamic in the building up of community is what I have called the 'sacrifice trap.' Once people are coerced, or even better, persuaded, into making sacrifices, their identity becomes bound up with the community organization for which the sacrifices were made" (Hardin \& Braden 1977, p. 288).

\section{IN CONCLUSION}

Community-based restoration is addressing environmental governance by infusing an eco-ethic into the American culture. The central idea of what J Dewitt termed 'civic environmentalism' is animating local communities to organize and task themselves with protecting and restoring their own jurisdictions without being forced to do so by central agencies (Dewitt 1994). Community-based restoration is civic environmentalism at its highest aspirations, a preemptive bottom-up approach for achieving environmental sustainability. A second generation of environmental sustenance is emerging, predicated on collaboration, integration, and local empowerment that transcends traditional command and control models, often beset with conflict, confrontation, and litigation. It is a proactive, not reactive, approach and it prides itself on positive reinforcement, the most effective force to operationally change behavior (Skinner 1953). To quote acclaimed geneticist D Suzuki, 'Just as the key to a species' survival in the natural world is its ability to adapt to local habitats, so the key to human survival will probably be the local community. If we can create vibrant, increasingly autonomous and self-reliant local groupings of people that emphasize sharing, cooperation, and living lightly on the Earth, we can avoid the fate warned of by Rachel Carson and the world scientists and restore the sacred balance of life' (Suzuki 1998, p. 8).

Restoration alone cannot keep pace with the magnitude of environmental destruction as the rate of damage often exceeds the rate of repair. No amount of ecosystem restoration will offset such seismic shifts in 
planetary metabolism poised to descend upon us sometime in this century from human impacts. Communitybased restoration is not a panacea for solving the world's environmental problems. However, social transformations are the solution and they often begin small, with great potential to exponentially amplify throughout a culture, particularly if they emerge at an optimum time in history. We are reminded of a Ms. Rosa Parks, who in 1955 refused to give up her seat on a bus in Montgomery, Alabama. From that simple solemn act the social impetus for civil rights was set irrevocably into motion. Or in 1930 when Ghandi marched over $200 \mathrm{~km}$ from his commune in Ahmedabad to Dandi, a city on the Indian ocean, and defied British law by making his own salt from the sea; thousands of Indians followed and were also imprisoned. The government of a free India was eventually realized in 1947.

$\mathrm{R}$ Carson sparked an environmental movement in 1962 through her publication of Silent Spring, which indicted industry for its irresponsible employment of pesticides to control insects that she predicted would one day create a dying world in which springtime would not bring forth new life. Her findings and forceful statements had an enormous impact that generated fierce concern and eventual legislation. J Wamsley, director of the Arrawong Earth Sanctuary in southern Australia, an organization like our Nature Conservancy, started out over thirty years ago as a one-man operation buying and restoring swamps in southern Australia for as little as 40 cents an acre. His large land mass is today referred to as the 'Little Jurassic Park' for a wide range of plant and animal species. Australian zoos have donated rare platypus' to his range, a range now the size of the state of Maine. About 50000 visitors passed through his sanctuary in 2001 (Daily \& Ellison 2002). As cultural anthropologist M Mead once stated, 'Never doubt that a small group of thoughtful committed citizens can change the world. Indeed, it is the only thing that ever has' (pers. comm. with the Margaret Mead Institute for Intercultural Studies, 2005).

Modern sociological, anthropological, and psychological theory show that self-interest is not the sole human driver. Human nature is far more complex and diversified than this and often reveals a wide range of instinctual constructive impulses toward altruism, gregariousness, and sacrifice, the very forces the act of community-based restoration invigorates. The human dichotomy, as Freud so well articulated, has not only a drive for self-destruction and annihilation, but the pursuit of pleasure, rejuvenation, and balance (Freud 1959). Conservation organizations recognize that our biological resources are declining at an accelerating rate. Habitat conservation appears to have proceeded along a reactive path of constant crisis management. Restoration, community-inspired, offers a proactive means to alter future trajectories not only by the physical modifications of an ecosystem, but by renewing us psychologically, emotionally, and spiritually. No other movement in Western civilization has prepared us for the environmental problems we must now confront in this century. Everything is at stake.

The recovery motif is on the rise because environmental decline prevails at all scales. Restoration has spawned a recovery narrative, suggesting that we are not only coexistent partners with the non-human world, but can act as potential healers toward an impaired Earth, replete with diagnosis and treatment. It signals a truce by the cessation of violence committed toward nature, replaced with purposeful constructive engagement. This emergent movement opens a path toward atonement, reconciliation, and ecopsychological health signifying, in a sense, a positive psychological mutation that reveals a compelling new story for global survival. We are beginning, though in the smallest incremental steps, to turn the tide for dealing with the monstrosity of human impacts on the entire world's biota by giving back to natural systems rather than taking. The start can begin by declaring 'Restoration Day' as a central focus for institutionalizing an annual celebration, for ritualizing the gift, for declaring a treaty with the natural world, and offering a stage for cultural-nature renewal on which new mythologies can be weaved. If, as literary writer J Joyce once stated, 'History is a nightmare from which I am trying to awake' (Joyce 1916, p. 28), then let us awaken to begin a new dream for the Earth.

The mark of a dynamic culture is possessing the capacity to reinvent our myths, for the stories of today are inadequate for meeting the survival demands of tomorrow. But how do we change our myths? What model do we use to integrate us with nature, for releasing cultural forms and motifs that capture a new paradigm for ecopsychological health? We need to be wisely active in nature for the hope that this form of engagement, like that found in community-based restoration, will place a stamp on the smallest parcel on Earth to influence the future health of the biosphere. Restorationists are starting the process of trying to recover the original 'garden' by actively entering into it to heal a depleted Earth. New kinds of stories, ways of thinking, and ethics are required for the twenty-first century. The conservation movement in the early twentieth century attempted to sustain both nature and humanity by saving places of pristine beauty. Restoration in the twenty-first century is restoring our connection with our planet. Communitybased restoration offers a powerful story for redeeming our fallen Earth by human labor, by allowing our alienated citizens to step back into the forest and putter in the garden once more. 
Acknowledgements. I am indebted to Prof J Cairns whose stimulating correspondence inadvertently formed the basis of many of the themes presented here. I am also indebted to the late J Campbell, renowned scholar of mythology, whose seminars I attended on world mythology greatly expanded my understanding of the collective unconscious. I deeply appreciate the guidance and insights from climate expert R Etkins throughout my career with NOAA.

Disclaimer: The contents of this manuscript represent the opinions of the author and not necessarily that of the US Federal Government or Employing Agency.

\section{LITERATURE CITED}

Bak P, Chen K (1991) Self-organized criticality. Scientific American, p 46-53

Berry T (1988) The dream of the Earth. Sierra Club Books: San Francisco, CA

Blais J, Schindler D, Muir D, Kimpe L, Donald D, Rosenburg B (1998) Accumulation of persistent organochlorine compounds in mountains of western Canada. Nature 395: 585-588

Broecker W (2003) Does the trigger for abrupt climate change reside in the ocean or in the atmosphere? Science 300: 1519-1522

Cairns J Jr (1996) Determining the balance between technological and ecosystem services. Engineering within ecological constraints. National Academy of Sciences, Washington, DC, p 13-30

Cairns J Jr (1998) Consilience or consequences: alternative scenarios for societal acceptance of sustainability initiatives. Renewable Resources J 16(2):6-12

Cairns J Jr (2000) World peace and global sustainability. Int J Sustainable Development 7:1-11

Calaprice A (2000) The expanded quotable Einstein. Princeton University Press and Hebrew University of Jerusalem: Princeton University, NJ

Campbell J (1951) The flight of the wild gander: explorations in the mythological dimensions of fairy tales, legends, and symbols. Harper Perennial Publishers: New York

Costanza R (1996) Designing sustainable ecological economic systems. Engineering within ecological constraints. National Academy of Sciences, Washington, DC

Daily G, Ellison K (2002) The new economy of nature: the quest to make conservation profitable. Island Press: Washington, DC

DeWitt J (1994) Civic environmentalism: alternatives to regulation in states and communities. Aspen Institute and National Academy of Public Administration, a division of Congressional Quarterly Inc, Washington, DC

Freud S (1959) Beyond the pleasure principle. Bantam Books: New York

Freud S (1961) Civilization and its discontents. W W Norton and Co: New York

Grossman D (2004) Spring forward. Scientific American

Hanson J (2005) A slippery slope: how much global warming constitutes dangerous anthropogenic interferences? Clim Change 68(3):269-279

Hardin G, Baden J (1977) Managing the commons. WH Freeman \& Co: San Francisco, CA

Hardin G (1968) The tragedy of the commons. Science 162:1243-1248

Hegel G (translated by Sibree J) (1956) The philosophy of history. Dover Publications, Inc.: New York

Holloway M (2003) The mutable brain. Scientific American

Jordan W (2000) Restoration, community, and wilderness. In:
Restoring nature: perspectives from the social sciences and humanities. In: Gobster P, Hull B (eds) Island Press: Washington, DC, p 21-36

Jowett B (1937) The dialogues of Plato. Random House: New York:

Joyce J (1986) Ulysses. The Gabler Edition, Vintage Books: New York

Kahn A (1966) The tyranny of small decisions: market failures, imperfections, and the limits of economics. Kyklos 19: 23-47

Koestler A (1967) Ghost in the machine. Henry Regnery Co: New York

Laing R (1967) The politics of experience. Pantheon Books: New York

Levitus S, Antonov J, Boyer T, Stephens C (2000) Warming of the world ocean. Science 287:2225-2228

Lorenz K (1963) On aggression. Bantam Books: New York

MacDonald F (1952) Plato's Cosmology (Timaeus). Humanities Press: New York

MacLean P (1958) Contrasting functions of limbic and neocortical systems of the brain and their relevance to psychophysiological aspects of medicine. Am J Medicine 25: 611-626

MacLean P (1964) Man and his animal brains. Modern Medicine 32:95-106

MacLean P (1973) The triune concept of the brain and behavior. University of Toronto Press: Toronto

Magnuson J (1990) Long-term ecological research and the invisible present. Scientific American, p 495-500

Metzner R (1999) Green psychology: transforming our relationship to the earth. Park Street Press: Rochester, VT

Miller I (2002) Washington in maps 1602-2000. Rizzoli International Publications: New York

Morris D (1967) The naked ape. McGraw Hill: New York

Myers N, Mittermeier R, Mittermeier C, da Fonseca G, Kent J (2000) Biodiversity hotspots for conservation priorities. Nature 403:853-858

Odum E (1971) Fundamentals of ecology. WB Saunders CO: Philadelphia, PA

Odum W (1982) Environmental degradation and the tyranny of small decisions. BioScience 32:728-729

Oeppen J, Vaupel J (2002) Broken limits to life expectancy. Science 296:1030-1031

Parmesan C, Yohe G (2003) A globally coherent fingerprint of climate change impacts across natural systems. Nature 421:37-42

President's Council on Sustainable Development (1996) Sustainable America: a new consensus. US population and sustainability. Washington, DC

Rennie J, DiChristina M, Rusting R (2003) Houston, you have a problem. Scientific American, p 10

Restak R (1991) The brain has a mind of its own: insights from a practicing neurologist. Crown Publishing: New York

Roszak T (1992) The voices of the earth: an explanation of ecopsychology. Simon and Schuster: New York

Sagan D, Margulis L (1989) Biosphere, from Earth to space. Enslow Publishing: New Jersey

Schroeder H (2000) The restoration experience: volunteers' motives, values, and concepts of nature. In: Restoring nature: perspectives from the social sciences and humanities. Gobster P, Hull B (eds). Island Press: Washington, DC, p 247-264

Sheldrake R (1991) The rebirth of nature: the greening of science and God. Bantam books: New York

Sirocko F (2003) What drove past teleconnections. Science 301:1336-1337

Suzuki D (1998) The sacred balance: rediscovering our place 
in nature. Prometheus Books: New York

Taylor K (1999) Rapid climate change. Am Scientist 87: $320-327$

Taylor P (1986) Respect for nature: a theory of environmental ethics. Princeton University Press: Princeton, NJ

Thomashow M (2002) Bringing the bioshere home: learning to perceive global environmental change. Massachusetts Institute of Technology Press: Cambridge, MA

Turner B, William, C, Kates R, Richards J, Mathews J, Meyers W (1990) The Earth as transformed by human action. Cambridge University Press: USA

Turner F (1985) Cultivating the American garden. Harpers

Editorial responsibility: Mary C. Batson (Managing Editor), Oldendorf/Luhe, Germany
Magazine, p 45-52

Underwood J (1992) Groping our way toward an environmental ethic. In: Voices from the environmental movement: perspectives for a new era. Snow D (ed). Island Press: Washington, DC

Watts A (1966) The book: on the taboo against knowing who you are. Pantheon Books: New York

Wilson EO (1992) The diversity of life. Harvard University Press: Cambridge, MA

Wilson EO (1993) Is humanity suicidal? New York Times Magazine May 30, Section:6, p. 24-27

Wilson EO (2002) The future of life. Vintage Books: New York

Submitted: February 12, 2005; Accepted: February 14, 2005

Proofs received from author(s): April 1, 2005

Published on the web: April 4, 2005 